\title{
VIRTUAL ENVIRONMENT IN CONTROL AND PROGRAMMING SYSTEM FOR RECONFIGURABLE MACHINING ROBOT
}

\author{
Zoran Dimic, Dragan Milutinovic, Sasa Zivanovic, Vladimir Kvrgic
}

Preliminary note

Robotic machining systems play an important role in modern manufacturing. The paper proposes the application of virtual robots for off-line programming. The reconfigurable machining robot, programmed in G-code, which can be directly used by $\mathrm{CNC}$ machine tool programmers and operators, is presented. The subject of study are 5- and 6-DOF vertical articulated robots that can be configured to emulate vertical and horizontal 5-axis spindle tilting machine tools. The considered machining systems are supported by equivalent virtual robots in the CAD/CAM environment and control system. Several test workpieces were machined to demonstrate the effectiveness of the proposed architecture.

Keywords: control; G-code; machining; programming; virtual robots

\section{Virtulano okruženje u sustavu za upravljanje i programiranje rekonfigurabilnog robota za obradu}

Prethodno priopćenje

Robotski obradni sustavi imaju značajnu ulogu u modernoj proizvodnji. Radom se predlaže primjena virtualnih robota za off-line programiranje. Prikazan je rekonfigurabilni robot za obradu, programiran u G-kôdu, koji se može izravno koristiti od strane programera i operatora CNC alatnih strojeva. Predmet istraživanja su petoosni i šestoosni roboti vertikalne zglobne konfiguracije koji mogu biti konfigurirani tako da emuliraju alatne strojeve s petoosnim vertikalnim i horizontalnim gibanjem glavnog vretena. Razmatrani obradni sustavi su podržani ekvivalentnim virtualnim robotima u CAD/CAM okruženju i sustavu upravljanja. U cilju demonstracije učinkovitosti predložene arhitekture, obrađeno je nekoliko probnih izradaka.

Ključne riječi: G-kod; programiranje; strojna obrada; virtuelni roboti; upravljanje

\section{Introduction}

The complexity of robot programming in machining applications originates from the fact that robot manufacturers usually use their own proprietary robot programming languages because no industry standard exists. This was a strong motivation for both researchers and leading world robot and CAD/CAM software manufactures to develop versatile robot programming methods which can be divided into two groups: (i) on-line by using standard teach-in robot techniques $[1 \div 3]$, and (ii) off-line by using versatile software solutions $[4,5]$ such as G-code translators, specific postprocessor solutions, etc. The aforementioned programming methods rely on traditional robot control systems with "normally closed" architecture [6], which is an obstacle to the integration of kinematic modules, programming languages, sensor systems, etc. The state-of-the-art robot programming methods in machining applications are tedious and timeconsuming tasks that require technical expertise. As stated in [7] robot programming represents the main obstacle for utilization of robots in machining applications, especially in small and medium-sized enterprises (SMEs). Finding skilled workers capable of operating with machining robots is the main difficulty for SMEs.

Robot machining simulation is very important in modern manufacturing $[4,8 \div 12]$. There are modern specialised CAD/CAM systems for robots, such as the Robotmaster [13], Robot Studio [14], and others. The state-of-the-art virtual robots can be classified into three main types: (i) virtual robots in $\mathrm{CAD} / \mathrm{CAM}$ systems, (ii) virtual robots in control systems, and (iii) virtual reality robots [15]. The subjects of our study are the first two types.

The first idea presented herein is the off-line robot programming by using standardised CAD/CAM, which includes robot machining simulation with movements of robot's 3D solid model segments including tool at the end. The second idea is to integrate a virtual robot into an open architecture control system EMC2 (Enhanced Machine Controller) [16], thus allowing machining simulation in OpenGL 3D environment. The virtual robot enables verification of G-code that includes the following:

- Check if the robot can execute the specified path within the limited joints motions ranges and speeds;

- Visual detection of collisions between the robot and the tool with the piece and jigs and fixtures.

The paper describes a reconfigurable robot for machining which can be directly used by CNC machine tool programmers and operators. It utilizes direct programming in G-code with equivalent virtual robot in the CAM toolpath programming environment. For G-code programming, we can use standardised CAD/CAM systems like PTC Creo, CATIA, Solid CAM, and others. Virtual robot is applied in EMC2 through usage of OpenGL [17] as an integral part of the control system. Several test workpieces were machined to demonstrate the effectiveness of developed off-line programming, simulation and control system for reconfigurable machining robot.

Results presented in the paper are a part of our broader research in the area of robotic machining that includes reconfigurability, control, programming, calibration and error compensation [9, 12]. Machining simulation embracing the analysis of cutting forces and machining error compensation is presented in our papers $[12,18]$.

The rest of the paper is organized as follows. In Section 2, the outline of the concept is given. Control and programming system and virtual robots are shown in Section 3. In Section 4, several test workpieces were 
machined for verification of the control and programming system for Reconfigurable Machining Robot presented.

\section{The outline of the concept}

In this paper, the idea is to perform 3- to 5-axis machining using commercially available 5- and 6-DOF articulated robots that emulate 5 -axis spindle tilting machine tools (Fig. 1) whereby G-code based programming in a standard $\mathrm{CAD} / \mathrm{CAM}$ environment is possible. Specialised commercially available 5-DOF machining robots with integrated motor spindle (Fig. 1a) emulate 5-axis vertical milling machines (X, Y, Z, A, B). Commercial multifunctional (standardised) 5-DOF robots (Fig 1b) can emulate 5-axis horizontal milling machines (X, Y, Z, A, B). Commercial multifunctional (standardised) 6-DOF robots can emulate 5-axis machine tools of the following configurations:

- 5-axis vertical milling machines (X, Y, Z, A, B) where all robot's axes are active, with the tool orientation angle $C=$ const., as shown in Fig. 1c (V). Another possibility is that the robot's axis $\theta_{6}$ is blocked (i.e. $\theta_{6}=0^{\circ}$ ), whereby specialised 5-DOF machining robot (Fig. 1a) is practically emulated.

- 5-axis horizontal milling machines (X, Y, Z, A, B) where all robot's axes are active, with the tool orientation angle $C=$ const., as shown in Fig. 1c $(\mathrm{H})$. Another possibility is that the robot's axis $\theta_{4}$ is blocked (i.e. $\theta_{4}=0^{\circ}$ ), whereby multifunctional (standardised) 5-DOF robot (Fig. 1b) is practically emulated.

- 5-axis vertical milling machines (X, Y, Z, A, C) with the robot's axis $\theta_{4}$ kept in a constant position $+90^{\circ}$ or $-90^{\circ}$ (Fig. 1d).

Experimental 6-DOF articulated robot from Fig. 2 was used for machining simulation, testing and verification of the developed prototype of control and programming system. Appropriate mechanical interfaces between the motor spindle and the interface plate of experimental robot (Fig. 2) enable emulation of 5-axis spindle tilting machine tools with 5- and 6-DOF articulated robots as shown in Fig 1. Fig. 4 shows CAD models of 6-DOF experimental machining robot which in 5- or 6-DOF robot configurations emulates 5 -axis spindle tilting machine tools according to Fig. 1. In all described cases machining is performed on the work table in front of the machine.
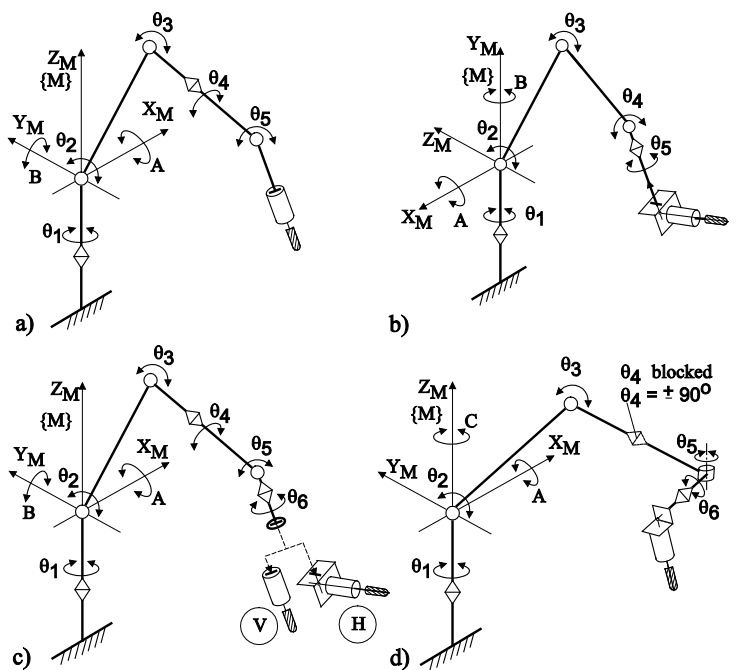

Figure 1 Commercially available 5- and 6-DOF articulated robots emulating 5 -axis spindle tilting machine tools

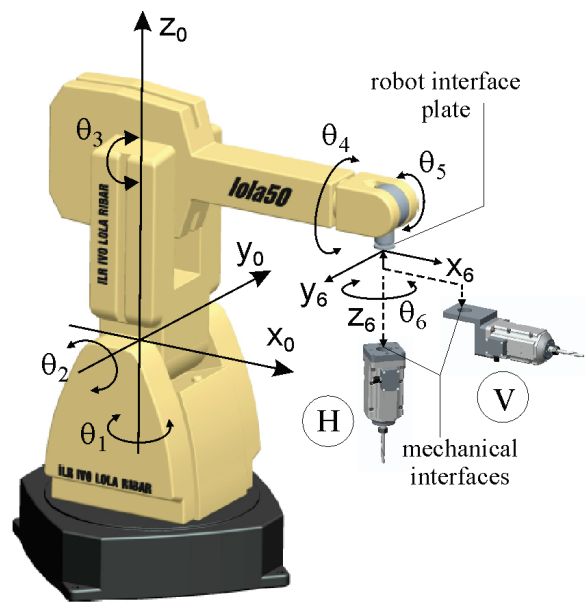

Figure 2 An example of 6-DOF robot reconfiguring
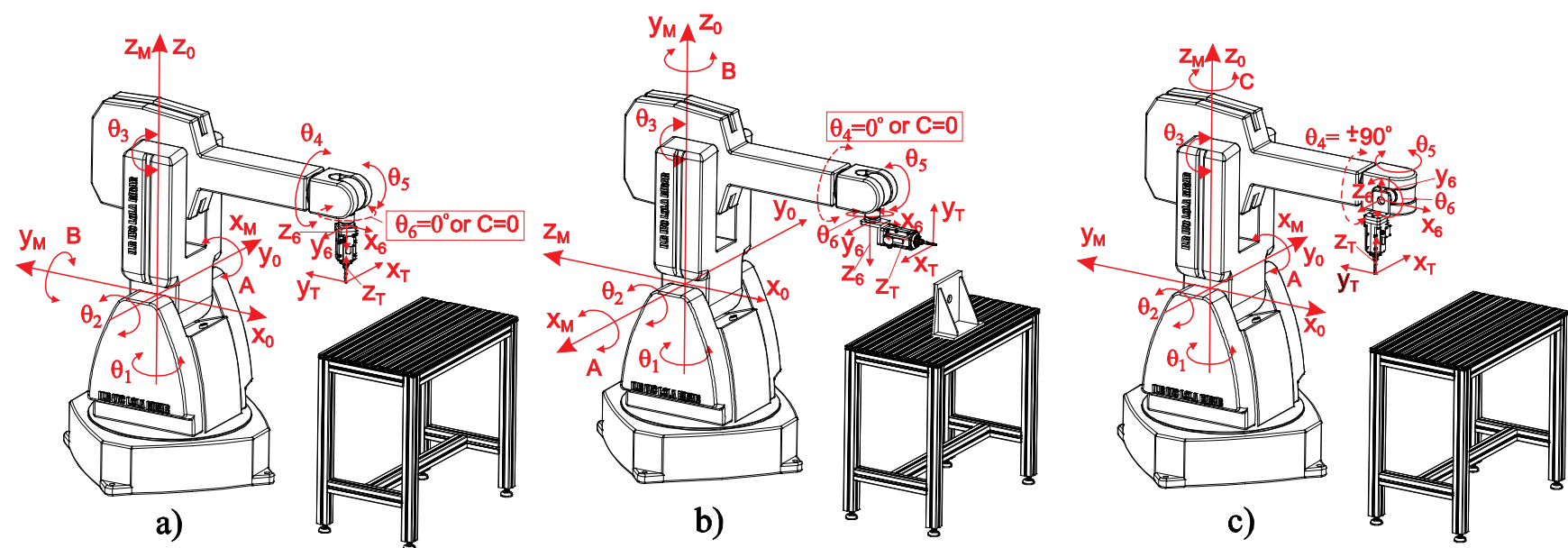

Figure 3 Experimental 6-DOF robot: a)configured as 5-DOF ( $\left.\theta_{6}=0\right)$ or 6-DOF robot $(C=0)$ to emulate 5-axis vertical milling machines $(\mathrm{X}$, Y, Z, A, B) spindle-tilting type; b) configured as 5-DOF $\left(\theta_{4}=0\right)$ or 6-DOF robot $(C=0)$ to emulate 5-axis horizontal milling machines $(\mathrm{X}, \mathrm{Y}, \mathrm{Z}$, A, B) spindletilting type; c) configured as 5-DOF ( $\theta_{4}=90$ or $\theta_{4}=-90$ ) robot to emulate 5-axis vertical milling machines $(\mathrm{X}, \mathrm{Y}, \mathrm{Z}, \mathrm{A}, \mathrm{C})$ spindle-tilting type 

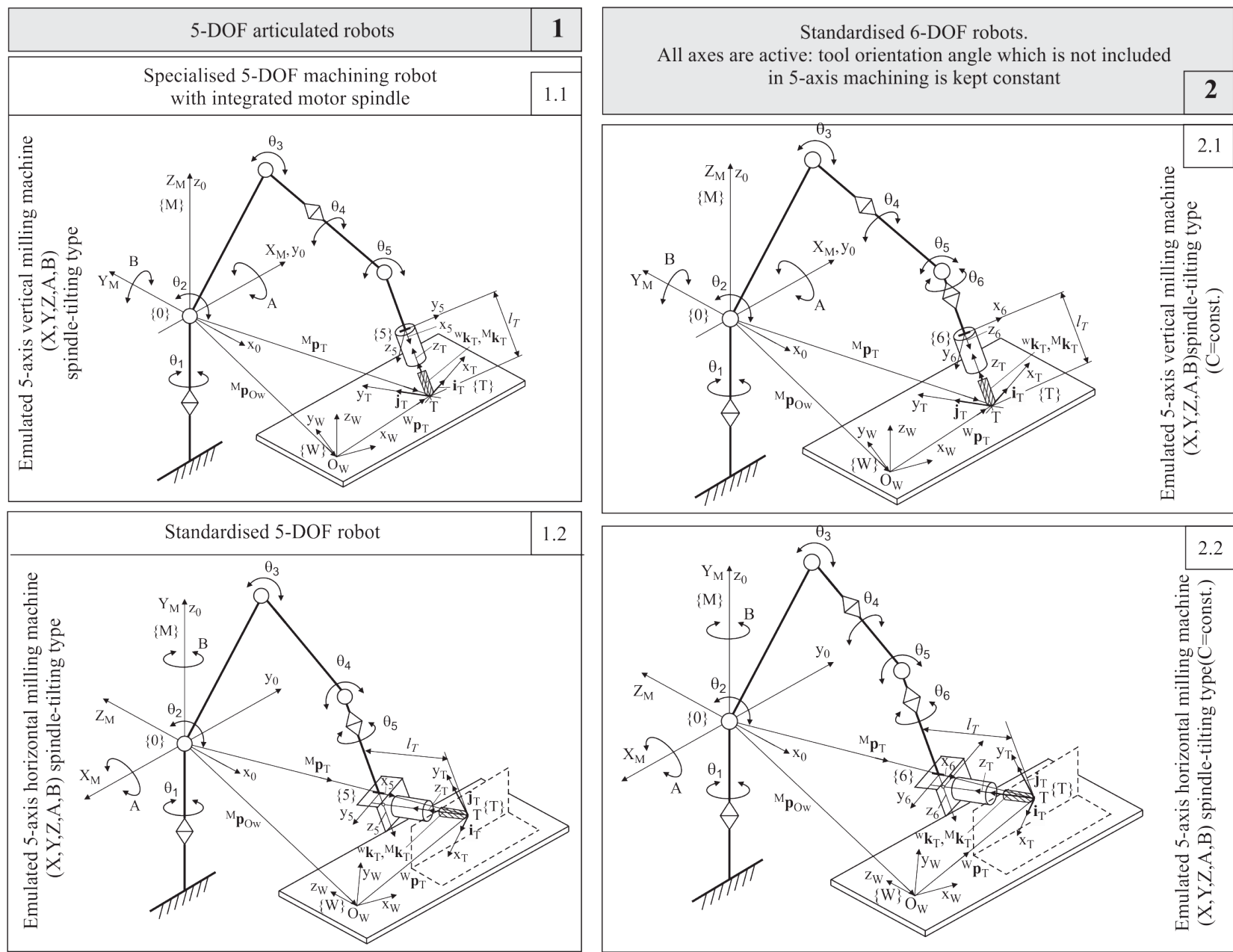

5-DOF robots emulated from standardised 6-DOF robot
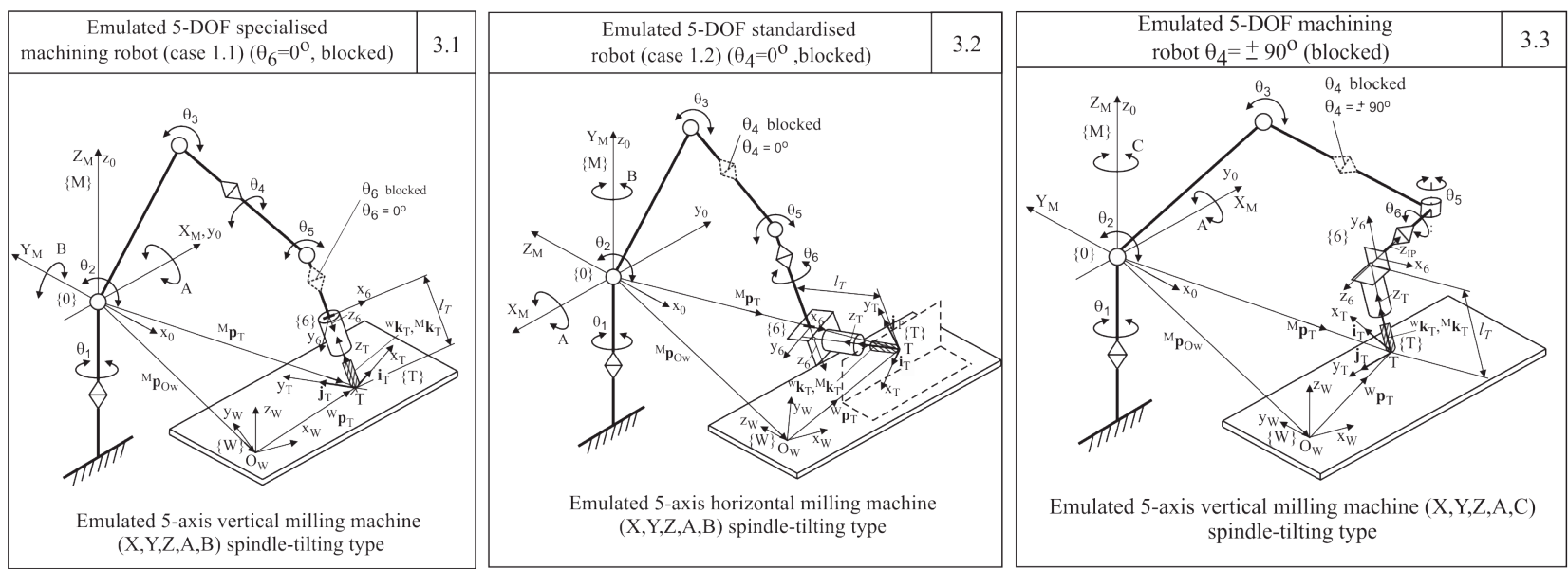

Figure 4 Geometric models of 5- and 6-DOF vertical articulated robots

Geometric models of 5- and 6-DOF vertical articulated robots (Fig.1 and Fig. 3) which can be configured and reconfigured to emulate different types of vertical and horizontal 5-axis spindle tilting machines are shown in Fig. 4. Displayed geometric models allow for a generalised modelling approach that represents a basis for the development of a reconfigurable control system.

The robots' reference frames $\{\mathrm{M}\}$ have been adopted according to the standard for relevant machine types [19]. Tool frames $\{\mathrm{T}\}$ are attached to the milling tools at tool tip $\mathrm{T}$ and frames $\{\mathrm{W}\}$ are attached to the workpieces. Vectors $\boldsymbol{v}$ referenced in frames $\{\mathrm{M}\}$ and $\{\mathrm{W}\}$ are denoted by ${ }^{M} \boldsymbol{v}$ and ${ }^{W} \mathbf{v}$. Joint coordinate vectors are represented as $\boldsymbol{\theta}=\left[\theta_{i}\right]^{\mathrm{T}}$ where, $i=1, \ldots, 5$ for 5-DOF articulated robots and $i=1, \ldots, 6$ for 6 -DOF articulated robot. The description of world coordinates is based on the tool path calculated by $\mathrm{CAD} / \mathrm{CAM}$ systems defined by a set of successive tool positions and orientations in workpiece frame $\{\mathrm{W}\}$, all cases in Fig. 4. The thus calculated tool path is machine independent and is known as a cutter location file (CLF). A tool pose is defined by the position vector of tool tip $\mathrm{T}$ in workpiece frame $\{\mathrm{W}\}$ as 
${ }^{W} \boldsymbol{p}_{T}=\left[\begin{array}{lll}x_{T w} & y_{T w} & z_{T w}\end{array}\right]^{\mathrm{T}}$ and tool orientation is defined by the unit vector of the tool axis as ${ }^{W} \boldsymbol{k}_{T}=\left[\begin{array}{lll}k_{T w x} & k_{T w y} & k_{T w z}\end{array}\right]^{\mathrm{T}}$. As the axes of frames $\{\mathrm{M}\}$ and $\{\mathrm{W}\}$ need not be parallel in a general case, the tool tip position vector ${ }^{M} \boldsymbol{p}_{T}$ and unit vector of tool axis direction in the robot's reference frame $\{\mathrm{M}\}{ }^{M} \boldsymbol{k}_{T}$ can be expressed as

$$
\begin{aligned}
{ }^{M} \boldsymbol{p}_{T} & =\left[\begin{array}{lll}
X_{M} & Y_{M} & Z_{M}
\end{array}\right]^{T}={ }^{M} \boldsymbol{p}_{O w}+{ }_{W}^{M} R \cdot{ }^{W} \boldsymbol{p}_{T} \\
{ }^{M} \boldsymbol{k}_{T} & =\left[\begin{array}{lll}
k_{T x} & k_{T y} & k_{T z}
\end{array}\right]^{T}={ }_{W}^{M} R \cdot{ }^{W} \boldsymbol{k}_{T}
\end{aligned}
$$

where ${ }^{M} \boldsymbol{p}_{O w}=\left[\begin{array}{lll}x_{O w} & y_{O w} & z_{O w}\end{array}\right]^{\mathrm{T}}$ is the position vector of the origin of workpiece frame $\{\mathrm{W}\}$ and ${ }_{W}^{M} R$ is an orientation matrix. It should be noted that the determination of the position vector ${ }^{M} \boldsymbol{p}_{O w}$ and orientation matrix ${ }_{W}^{M} R$ of workpiece frame $\{\mathrm{W}\}$ is conducted according to the procedure for 5-axis $\mathrm{CNC}$ machine tools without changing the G-code.

In this stage of development, the system makes it possible to work with parallel coordinate frames $\{\mathrm{M}\}$ and $\{\mathrm{W}\}$ only, which means

${ }^{M} \boldsymbol{p}_{T}=\left[\begin{array}{lll}X_{M} & Y_{M} & Z_{M}\end{array}\right]^{\mathrm{T}}={ }^{M} \boldsymbol{p}_{O w}+{ }^{W} \boldsymbol{p}_{T}$

and

${ }^{M} \boldsymbol{k}_{T}={ }^{W} \boldsymbol{k}_{T}=\left[\begin{array}{lll}k_{T x} & k_{T y} & k_{T z}\end{array}\right]^{\mathrm{T}}$

To complete the vectors of world coordinates, it is also necessary to determine tool orientation angles (A, B) and $(\mathrm{A}, \mathrm{C})$ which define only the direction of tool axis $z_{T}$ for the relevant cases from Fig. 4.

The description of the position and orientation of one frame relative to another, e.g. in this case of the frame $\{\mathrm{T}\}$ relative to the frame $\{\mathrm{M}\}$, can be represented through homogenous coordinate transformation matrix $4 \times 4$, $[20 \div 22]$, as

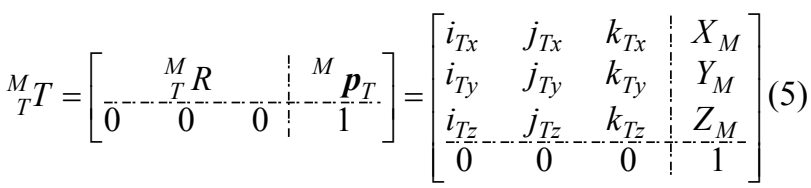

where rotation matrix ${ }_{T}^{M} R$ represents the orientation, while vector ${ }^{M} \boldsymbol{p}_{T}$ represents the position of the frame $\{\mathrm{T}\}$ with respect to the robot's reference frame $\{\mathrm{M}\}$. To bring the tool axis, i.e. the axis $z_{T}$ of the frame $\{\mathrm{T}\}$, to a desirable angular position with respect to the frame $\{M\}$, the frame $\{\mathrm{T}\}$ must be rotated appropriately about the axes of the coordinate frame $\{\mathrm{M}\}$ :

Emulation of vertical milling machine $(X, Y, Z, A, B)$ tilting spindle includes case (1.1), case (2.1) and case (3.1)

To bring the tool axis $z_{T}$ of the frame $\{\mathrm{T}\}$ to a desirable angular position with respect to the frame $\{M\}$, the frame
$\{\mathrm{T}\}$ must be rotated first about axis $X_{M}$ by angle $\mathrm{A}$, and then about axis $Y_{M}$ by angle $\mathrm{B}$, as prescribed by the convention for 5-axis tilting spindle machine tools $(\mathrm{X}, \mathrm{Y}$, $\mathrm{Z}, \mathrm{A}, \mathrm{B})$. The equivalent rotation matrix ${ }_{T}^{M} R$ can be further derived as

$$
{ }_{T}^{M} R=R_{Y_{M, B}} \cdot R_{X M, A}
$$

where rotation matrices $R_{X_{M, A}}$ and $R_{Y_{M, B}}$ are basic rotation matrices $[9,20,23]$. As the orientation of tool axis $z_{T}$ specified by unit vector ${ }^{M} \boldsymbol{k}_{T}=\left[\begin{array}{lll}k_{T x} & k_{T y} & k_{T z}\end{array}\right]$ is of interest only, the angles A and $\mathrm{B}$ can be determined by equating ${ }^{M} \boldsymbol{k}_{T}$ with the corresponding members of matrix ${ }_{T}^{M} R$ from Eq. (6). This way, the world coordinate vectors for the case (1.1), (2.1) and (3.1) (Fig. 4) can be expressed as $\boldsymbol{x}=\left[\begin{array}{lllll}X_{M} & Y_{M} & Z_{M} & A & B\end{array}\right]^{\mathrm{T}}$.

Emulation of horizontal milling machine $(X, Y, Z, A, B)$ tilting spindle type includes cases (1.2), (2.2), and (3.2)

In these cases, to bring tool axis $z_{T}$ of frame $\{\mathrm{T}\}$ to a desirable angular position with respect to the frame $\{\mathrm{M}\}$, the tool frame $\{\mathrm{T}\}$ must be rotated first about axis $Y_{M}$ by the angle $\mathrm{B}$ and then about axis $X_{M}$ by the angle $\mathrm{A}$, as prescribed by the convention for this machine type. The equivalent rotation matrix ${ }_{T}^{M} R$ can be further derived as

${ }_{T}^{M} R=R_{X M, A} \cdot R_{Y_{M, B}}$

As the orientation of tool axis $z_{T}$ specified by unit vector ${ }^{M} \boldsymbol{k}_{T}=\left[\begin{array}{lll}k_{T x} & k_{T y} & k_{T z}\end{array}\right]^{\mathrm{T}}$ is of interest only, the angles $\mathrm{A}$ and $\mathrm{B}$ can be determined by equating ${ }^{M} \mathbf{k}_{T}$ with the corresponding members of matrix ${ }_{T}^{M} R$ from Eq. (7) $[20,23]$. This way, the world coordinate vectors for the cases (1.2), (2.2) and (3.2) (Fig. 4) can be expressed as $\boldsymbol{x}=\left[\begin{array}{lllll}X_{M} & Y_{M} & Z_{M} & A & B\end{array}\right]^{\mathrm{T}}$.

Emulation of vertical milling machine $(X, Y, Z, A, C)$ tilting spindle type relates to the case (3.3)

In this case, to bring the tool axis $z_{T}$ of the frame $\{\mathrm{T}\}$ to a desirable angular position with respect to the frame $\{\mathrm{M}\}$, the tool frame $\{\mathrm{T}\}$ must be rotated first about the axis $X_{M}$ by the angle $\mathrm{A}$ and then about the axis $Z_{M}$ by the angle $\mathrm{C}$, as prescribed by the convention for this machine type. The equivalent rotation matrix ${ }_{T}^{M} R$ can be further derived as

${ }_{T}^{M} R=R_{Z M, C} \cdot R_{X M, A}$

As the orientation of tool axis $z_{T}$ specified by unit vector ${ }^{M} \boldsymbol{k}_{T}=\left[\begin{array}{lll}k_{T x} & k_{T y} & k_{T z}\end{array}\right]^{\mathrm{T}}$ is of interest only, the angles $\mathrm{A}$ and $\mathrm{C}$ can be determined by equating ${ }^{M} \boldsymbol{k}_{T}$ with the corresponding members of matrix ${ }_{T}^{M} R$ from Eq. (8) 
$[20,23]$. This way, the world coordinate vectors for the case (3.3) (Fig. 4) are expressed as $\boldsymbol{x}=\left[\begin{array}{lllll}X_{M} & Y_{M} & Z_{M} & A & C\end{array}\right]^{\mathrm{T}}$.

It should be noted here that in the cases where the 6-DOF robot performs 5-axis machining, the angle which is not included in world coordinate vectors is taken to be blocked (i.e. $\mathrm{C}=0$ ).

The modelling approach, inverse and direct kinematics, workspace analysis of reconfigurable machining robot programmed in G-code are described in $[9,10]$.

In the case of very complex workpieces requiring multifaceted machining, the proposed control and programming system allows robot reconfigurations (with no physical interventions) into different vertical or horizontal 5-axis machines. This solves the problems of robot singularity and the problems of limited joint motions. As an example, Fig. 5 shows a case where complex surfaces on the upper side of the workpiece would be machined using programmes for 5-axis vertical machine $\left(X_{V}, Y_{V}, Z_{V}, A_{V}, C_{V}\right)$, case (3.2), whereas complex surfaces on the lateral sides of the workpiece would be machined using programmes for 5-axis horizontal machine $\left(\mathrm{X}_{\mathrm{H}}, \mathrm{Y}_{\mathrm{H}}, \mathrm{Z}_{\mathrm{H}}, \mathrm{A}_{\mathrm{H}}, \mathrm{B}_{\mathrm{H}}\right)$, case (3.3).

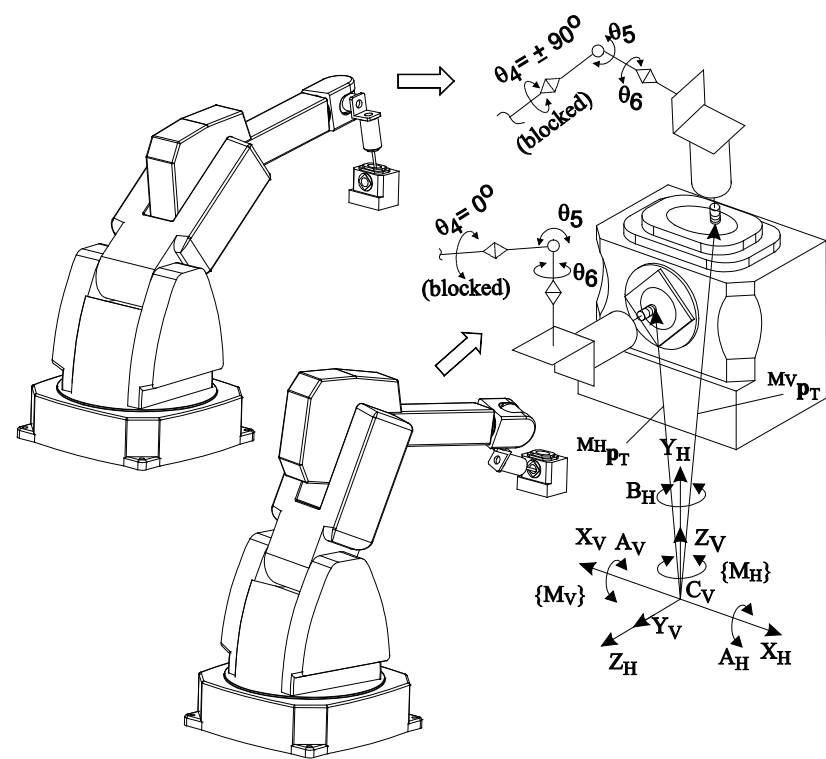

Figure 5 An example of robot reconfiguring for multifaceted machining

\section{Control and programming system with virtual robots}

The development of the control and programming system prototype for 5-axis machining by articulated robots with 5- and 6-DOF is based on EMC2 software. EMC2 was initially created by the NIST (National Institute of Standards and Technology) and is a free software released under the terms of the GPL (General Public License) [24, 25].

Fig. 6 shows a simplified structure of the first control and programming system. As it is obvious, the programming part is very conventional, with the use of appropriate postprocessor to convert CLF into G-code, according to ISO 6983. This means that the programmer starts from the workpiece CAD model in a common way, in this case in CAD/CAM system, generating CLF. The generated tool path is tested through the $\mathrm{NC}$ check (animated display of tool path and material removal). Using the configured postprocessor for the vertical (V) or horizontal $(\mathrm{H})$ 5-axis milling machines $(\mathrm{X}, \mathrm{Y}, \mathrm{Z}, \mathrm{A}, \mathrm{B})$ or (X,Y,Z,A,C) spindle-tilting type, post-processing of CLF is done to obtain the program in G-code, which is transferred to the robot control system. In the control system a choice is made for vertical (V) or horizontal $(\mathrm{H})$ 5 -axis milling machine with appropriate transformation matrices ${ }_{T}^{M} T,{ }_{0}^{M} T$ and ${ }_{T}^{6} T$. For testing the functions of inverse and direct kinematics $[9,10]$ and collision detection, a virtual robot is configured. The virtual robot is configured using several predefined Python classes [16] and OpenGL in EMC2. Based on inverse and direct kinematics equations, kinematic module is programmed in $\mathrm{C}$ language and is integrated in EMC2 software system (Fig. 6).

\subsection{Virtual robots in programming system}

The configured virtual robot is used for the simulation of tool path generated in CAD/CAM (PTC Creo 2 [26]) environment, which is important in order to: (i) configure the off-line programming environment, (ii) verify program before machining, (iii) detect collision during program execution $[27 \div 30]$.

The virtual robot in $\mathrm{CAD} / \mathrm{CAM}$ environment, contains all relevant components of the robot mechanism, including kinematic relations between moving segments. In-between the robot segments are rotary axes (Pin) (Fig. $7 a)$. This virtual robot enables the motion of segments in ranges defined in the real robot (Fig. 7b) which is of particular importance for the identification of possible collisions during the simulation process. Tool tip moves according to the tool path, which was previously obtained from the CAD/CAM. Post-processing is the same as for the 5-axis vertical or horizontal milling machine, spindle tilting type. The postprocessor is configured using the post-processor generator in the $\mathrm{CAD} / \mathrm{CAM}$ system.

\subsection{Virtual robots in control system}

Reconfigurable machining system has been tested in our laboratory. Since it is a robotic system with complex kinematics, a virtual robot is also included in the control system.

Virtual robots are configured in the programming language Python using OpenGL [17]. The algorithm for model configuration is shown in Fig. 8.

The modelling process of the virtual model boils down to the input of coordinates which define elementary geometric bodies. Simplified CAD model can be generated using the geometric primitives such as Box, Cylinder, Sphere, etc. It can also be made by using AsciiSTL or AsciiOBJ file for each robot segment, as displayed in Fig. 8. As a result, one gets a virtual robot in OpenGL which integrates in graphical interface Axis of EMC2. Simulations are performed to verify the program before machining in real time control unit.

For each configuration of 5- and 6-DOF machining robot (Fig. 4) a virtual robotic machining system was configured (Fig. 9). 


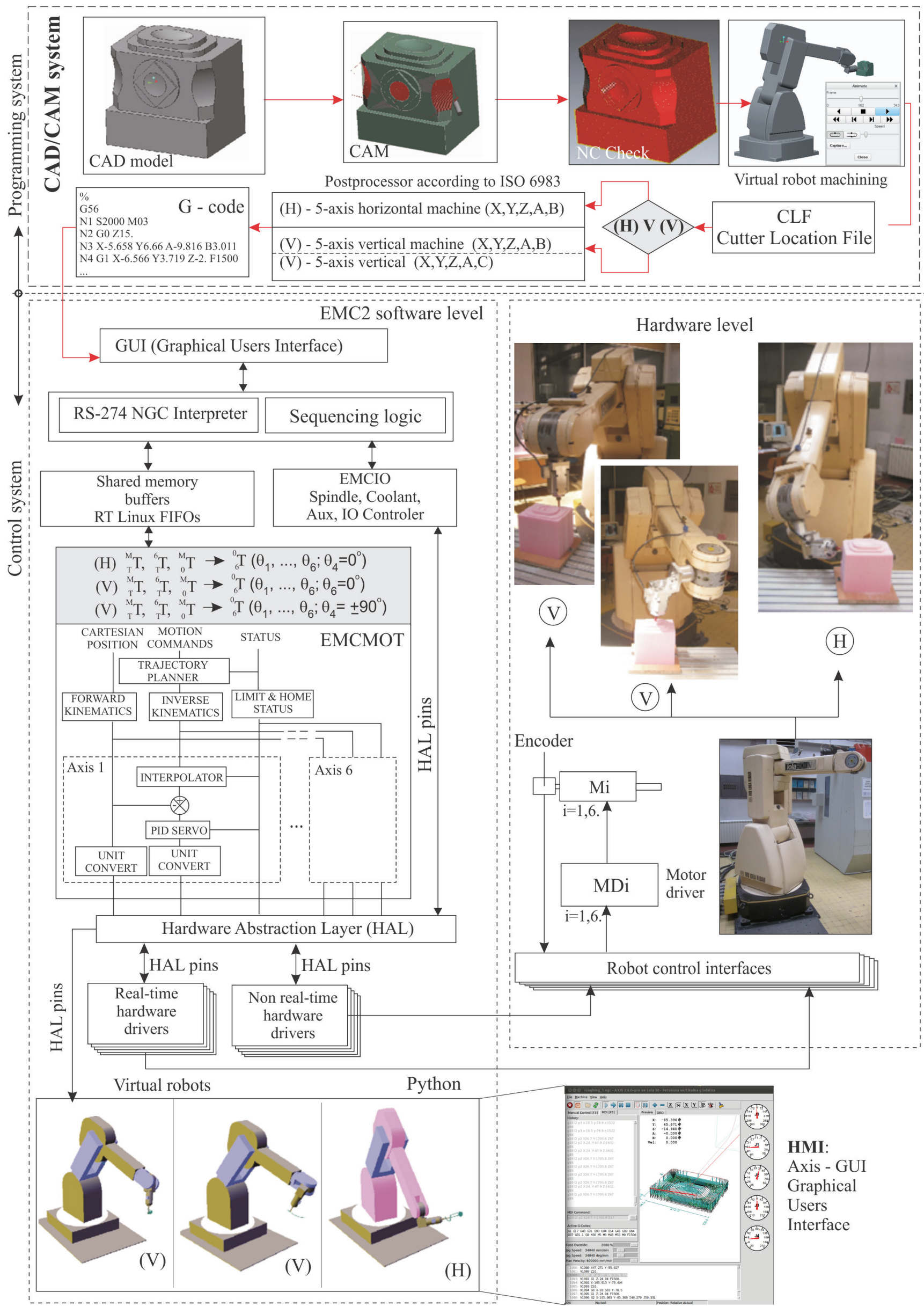

Figure 6 Control and programming system 
Simulations of robotic machining systems are performed for the purpose of:

- Testing each configuration of robotic machining system (cases (1.1), (1.2), (2.1), (2.2), (3.1), (3.2) and (3.3)), which includes checking the implemented kinematic algorithms, the functionality of software hardware interfaces and the newly created HMI (Human Machine Interface);

- Verifying and simulating machining programme on selected emulated 5-axis milling machine, verifying that the robot can execute the specified paths within the limited joint motion ranges and speeds. Visual detection is possible in case of collision between the robot and the equipment, jigs and fixtures.

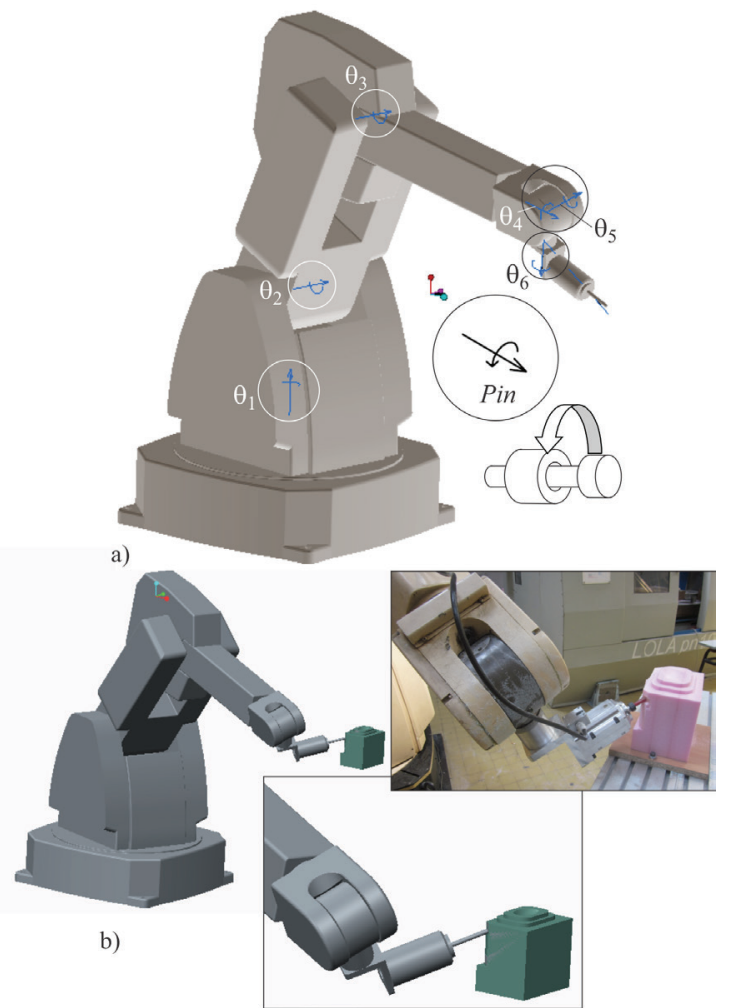

Figure 7 Virtual machining robot in programming system and real robot

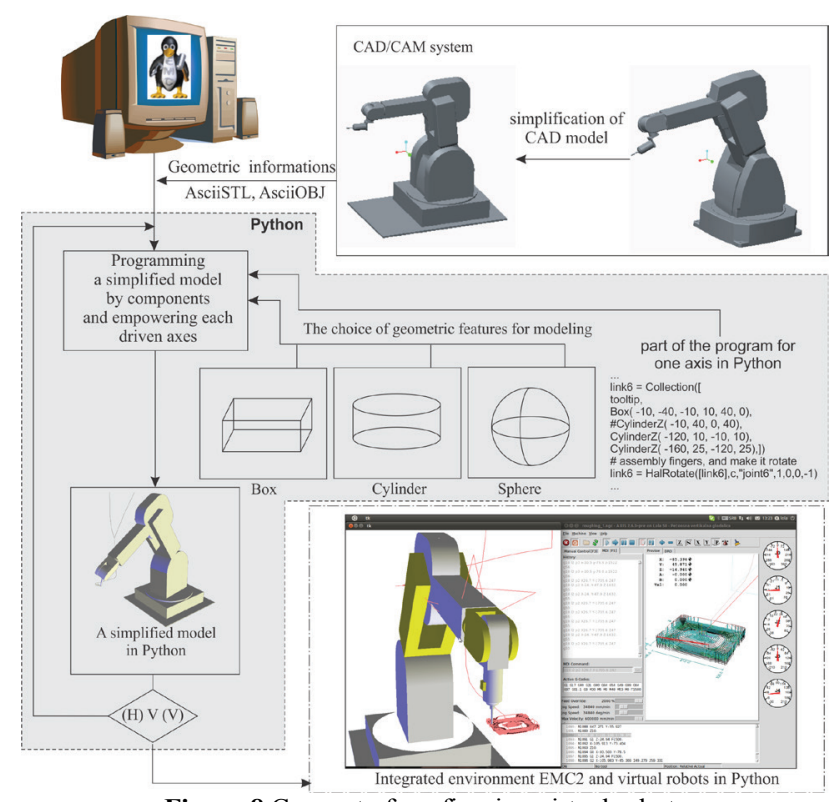

Figure 8 Concept of configuring virtual robots
After these verifications, the programme can be safely executed on a real 5- or 6-DOF robotic machining system.

Virtual simulation allows off-line programming with verification and testing on a remote site without machine engagement. Since there was a word about the real-time simulation of the machine, it can also be used for monitoring of machining operation from remote location. Working in the virtual environment is also suitable for training and education in programming of such manufacturing systems.

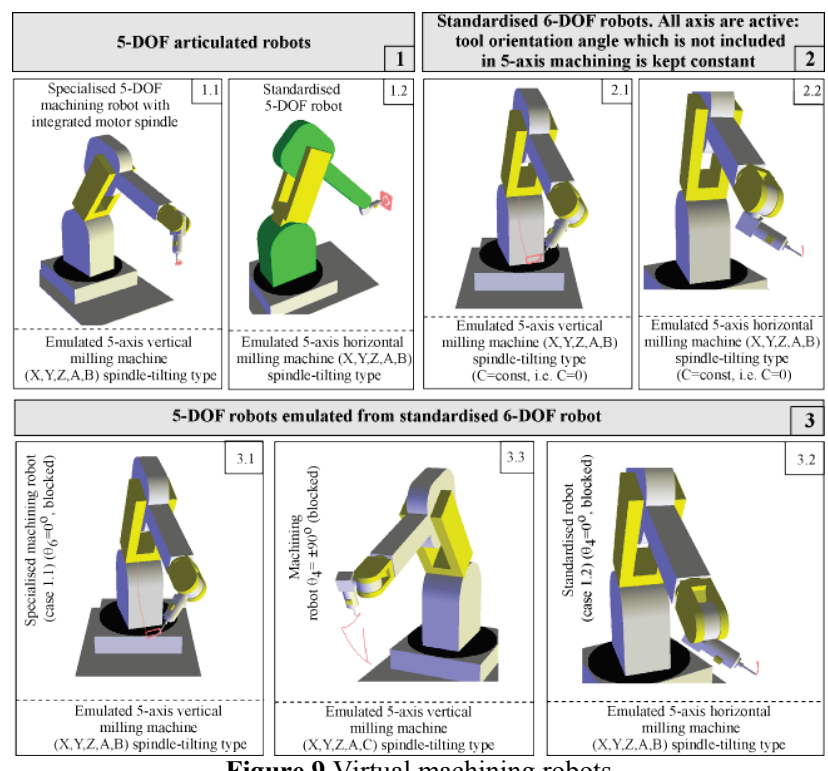

Figure 9 Virtual machining robots

\section{Experiments}

The aim of machining experiments was to test the capabilities of the developed system.

The PTC Creo 2.0 was used for the experiments with the idea that the programming of machining robot and machining itself is done in exactly the same way as it is done on a 5-axis vertical milling machines (X, Y, Z, A, B) and $(\mathrm{X}, \mathrm{Y}, \mathrm{Z}, \mathrm{A}, \mathrm{C})$ or 5-axis horizontal milling machine (X, Y, Z, A, B) spindle-tilting type. Machining experiments were conducted to machine two workpieces of light materials and lower tolerance. Prior to machining the programs are tested in EMC2 on a virtual machining robot in order to perform the final verification of the program (Fig. 9 and Fig. 10).

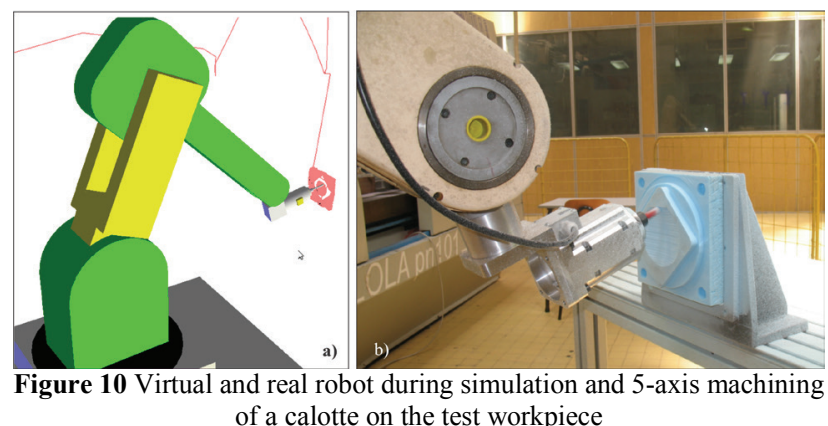

To verify the control and programming system with virtual robots, the test workpiece was machined. Fig. 10a shows virtual robot and Fig. 10b shows a real robot doing 5 -axis machining of a calotte on the test workpiece. This 
experiment employs standardized 6-DOF robot, case (2.2).

To verify the robot reconfigurability (with no physical interventions) a test workpiece requiring multifaceted machining (Fig. 11) was designed and performed.

Fig. 11a shows a CAD model of the designed test workpiece on which machined surfaces (that were machined) are indicated as follows:

- 3-axis machining 3V (Fig. 11c) and 5-axis machining $5 \mathrm{~V}$ (Fig. 11d) on an emulated 5-axis vertical tilting spindle milling machine (X, Y, Z, A, C), case (3.3);

- 3-axis machining $3 \mathrm{H}$ (Fig. 11b) and 5-axis machining $5 \mathrm{H}$ (Fig. $11 \mathrm{f}$ and Fig. 11g) on an emulated 5-axis horizontal tilting spindle milling machine $(\mathrm{X}, \mathrm{Y}, \mathrm{Z}$, A, B), case (3.2);

- Finally machined workpiece is shown in Fig 11e.

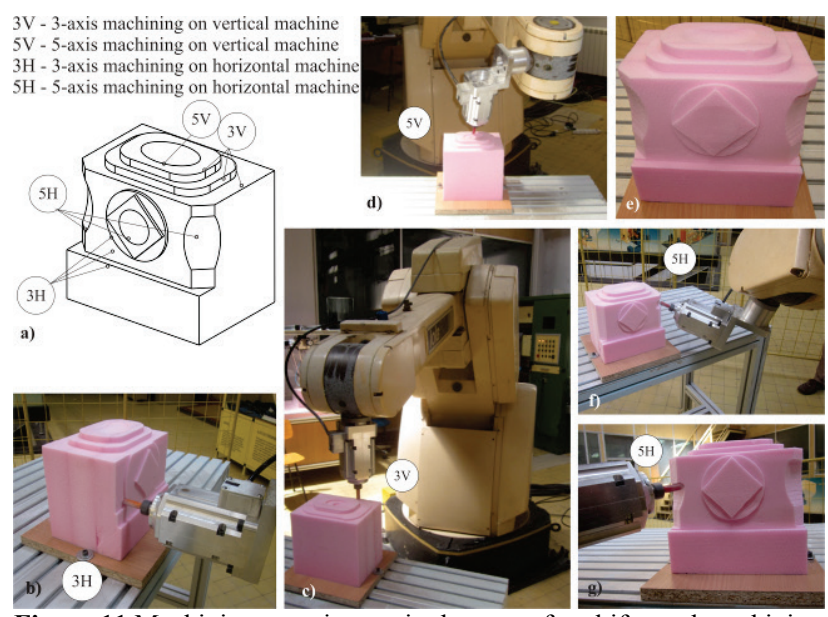

Figure 11 Machining experiments in the case of multifaceted machining

These experiments have confirmed that it is possible to realise a reconfigurable machining robot for different versions of emulated 5-axis milling machines, shown in Fig. 4.

\section{Conclusion}

The paper presents the concept of reconfigurable machining robot and its equivalent virtual robot in the control and programming system. In this stage, the proposed concept of control system with programming in G-code is based on EMC2 software and generalized modelling approach of 5- and 6-DOF vertical articulated robots which can be configured to emulate vertical and horizontal 5 -axis machine tools with spindle-tilting.

The presented control and programming system with virtual robots helps users to utilize robots in machining applications, especially in SMEs, allowing control and programming to become intuitive, cost-effective, quickly implemented, without the usage of the robot specific language.

The proposed control architecture is a low-cost and low-setup time system, where no advanced robot programming skills are required from the operator, which means that it can be directly used by CNC machine tool programmers and operators. The developed system provides an integrated reconfigurability of the machining robot that allows multifaceted machining with different robot configurations in one workpiece setup.
Experimental prototype of the control and programming system for 5 -axis machining by articulated 5- and 6-DOF robots indicates that it is possible to encapsulate robots' kinematics into a control system enabling the use of industrial robots for machining applications in the same way as commercially available machine tools.

\section{Acknowledgements}

The authors would like to thank the Ministry of Education, Science and Technological Development of the Republic of Serbia for providing financial support that made this work possible.

\section{References}

[1] Shirase, K.; Hirao, M.; Yasui, T. End Milling for Articulated Robot Application. $2^{\text {nd }}$ Report. Copy Miling Based on Sensor Feedback Teaching Program. // Transactions of the Japan Society of Mechanical Engineers Series C 60. 571(1994), pp. 1077-1083. DOI: 10.1299/kikaic.60.1077

[2] Solvang, B.; Sziebig, G.; Korondi, P. Vision Based Robot Programming. // Networking, Sensing and Control. ICNSC 2008. IEEE International Conference on. 2008, pp. 949954.

[3] Pan. Z.; Zhang H. Robotic machining from programming to process control: a complete solution by force control. // Industrial Robot: An International Journal. 35, 5(2008), pp. 400-409.

[4] DePree, J.; Gesswein, C. Robotic machining white paper project-Halcyon Development, (2008). URL: http://www.robotics.org/robotic-content.cfm/Robotics/ Halcyon-Development-RIA/id/43. (21.01.2015)

[5] Seventh Framework Programme. Plug-and-produce COmponents and METhods for adaptive control of industrial robots enabling cost effective, high precision manufacturing in factories of the future, URL: http://www.cometproject.eu. (27.1.2015).

[6] Zhang, H.; Wang, J.; Zhang, G.; Gan, Z.; Pan, Z.; Cui, H.; Zhu, Z. Machining with flexible manipulator: toward improving robotic machining performance // Proceedings of IEEE/ASME International Conference on Advanced Intelligent Mechatronics. 2005, pp. 1127-1132. DOI: 10.1109/AIM.2005.1511161

[7] Neto, P.; Mendes, N.; Araújo, R.; Pires, J. N.; Moreira A. P. High-level robot programming based on CAD: dealing with unpredictable environments. // Industrial Robot: An International Journal. 39, 3(2012), pp. 294-303.

[8] Li W.; Red E.; Jensen G.; Evans M. Reconfigurable mechanisms for application control (RMAC): applications. // Computer-Aided Design \& Applications. 4, 1-4(2007), pp. 549-556.

[9] Milutinovic, D.; Glavonjic, M.; Slavkovic, N.; Dimic, Z.; Zivanovic, S.; Kokotovic, B.; Tanovic, Lj. Reconfigurable robotic machining system controlled and programmed in a machine tool manner. // International Journal of Advanced Manufacturing Technology. 53, 9-12(2011), pp. 1217-1229.

[10] Milutinovic, D.; Slavkovic, N.; Zivanovic, S.; Glavonjic, M. Low-cost control and programming system for five-axis machining by articulated robots with 5 and 6 dof. // Proceedings of 5th International Conference on Manufacturing Engineering ICMEN / Thessaloniki Greece, 2014, pp. 133-142.

[11] Živanović, S.; Dimić, Z.; Slavković, N.; Milutinović, D.; Glavonjić, M. Configuring of virtual robot for machining and application in off-line programming and education. // 
Proceedings of 1 st International Scientific Conference Conference on Mechanical Engineering Technologies and Applications COMETa / Jahorina, B\&H, 2012, pp. 125132.

[12] Slavkovic, N.; Milutinovic, D.; Glavonjic, M. A method for off-line compensation of cutting force-induced errors in robotic machining by tool path modification. // International Journal of Advanced Manufacturing Technology. 70, 9-12(2014), pp. 2083-2096. DOI: 10.1007/s00170-013-5421-z

[13] Robotmaster. URL: http://www.robotmaster.com/ (29.01.2015)

[14] RobotStudio. URL: http://new.abb.com/products/robotics/ robotstudio (29.01.2015)

[15] Vrax, URL: http://www.instantreality.org/vrax/ (29.01.2015)

[16] LinuxCNC-Vismach. URL: http://wiki.linuxcnc.org/cgibin/wiki.pl?Vismach. (29.01.2015)

[17] The Industry's Foundation for High Performance Graphics. URL: http://www.opengl.org (21.01.2015)

[18] Kokotovic, B.; Glavonjic, M. Predicting of milling forces in virtual manufacturing system // Tehnicki vjesnik-Technical Gazette. 20, 6(2013), pp. 1027-1035.

[19] ISO 841:2001 Industrial automation systems and integration - Numerical control of machines - Coordinate system and motion nomenclature. URL: http://www.iso.org/iso/catalogue_detail.htm?csnumber=239 49. (29.01.2015).

[20] Craig, J. J. Introduction to robotics: mechanics and control, 2nd edn. Addison-Wesley, 1989.

[21] Paul, R. P. Robot Manipulators: mathematics, programming and control. MIT, Boston, 1981

[22] Fu, K. S.; Gonzalez, R. C.; Lee, C. S. G. Robotics: control, sensing, vision, and intelligence. McGraw-Hill, New York, 1987.

[23] Lee, R. S.; She, C. H. Developing a postprocessor for three types of five-axis machine tools. // International Journal of Advanced Manufacturing Technology. 13, 9(1997), pp. 658-665. DOI: 10.1007/BF01350824

[24] Linux CNC: Software for real-time control, 2015. URL: http://www.linuxenc.org/ (21.1.2015)

[25] Real-Time Control Systems Library - Software and Documentation. URL: http://www.isd.mel.nist.gov/ projects/rcslib (21.01.2015)

[26] PTC Creo. URL: http://creo.ptc.com/ (29.01.2015)

[27] Zivanovic, S.; Glavonjic, M.; Milutinovic, D. Configuring A Mini-Laboratory and Desktop 3-Axis Parallel Kinematic Milling Machine. // Strojniški vestnik - Journal of Mechanical Engineering. 61, 1(2015), pp. 33-42. DOI: 10.5545/sv-jme.2013.1619

[28] Maronek, M.; Barta, J.; Ertel, J. Inaccuracies of industrial robot positioning and methods of their correction. // Tehnicki Vjesnik-Technical Gazette. 22, 5(2015), pp. 12071212, DOI:10.17559/TV-20140416123902

[29] Svaco, M.; Jerbic, B; Suligoj, F. Autonomous robot learning model based on visual interpretation of spatial structures. // Transactions of FAMENA. 38, 4(2014), pp. 13-28

[30] Pasztor, A. Gathering simulation of real robot swarm. // Tehnicki Vjesnik-Technical Gazette. 21, 5(2014), pp. 10731080 .

\section{Authors' addresses}

Zoran Dimic, M.Sc.

Lola Institute,

Kneza Viseslava 70A, 11030 Belgrade, Republic of Serbia zoran.dimic@li.rs

Dragan Milutinovic, Ph.D.

University of Belgrade, Faculty of Mechanical Engineering, Kraljice Marije 16, 11120 Beograd 35, Republic of Serbia dmilutinovic@mas.bg.ac.rs

Sasa Zivanovic, Ph.D.

University of Belgrade, Faculty of Mechanical Engineering, Kraljice Marije 16, 11120 Beograd 35, Republic of Serbia szivanovic@mas.bg.ac.rs

\section{Vladimir Kvrgic, Ph.D.}

Lola Institute,

Kneza Viseslava 70A, 11030 Belgrade, Republic of Serbia vladimir.kvrgic@li.rs 